\title{
A gap analysis of the South African innovation system for water
}

\author{
Jeremy Rose' and Kevin Winter ${ }^{1 *}$ \\ 'Department of Environmental \& Geographical Science, University of Cape Town, P/Bag X3, Rondebosch, 7701, Cape Town, South Africa
}

\begin{abstract}
This paper draws on the innovation literature to analyse the South African system of innovation for water. Two major approaches to science and innovation from the innovation systems literature are described and compared: the neoclassical or 'market-failure' linear model of innovation, and the more complex and more recent innovation systems approach. It is argued that the innovation systems approach is a useful basis of analysis because of its emphasis on the diffusion of knowledge and the factors which tend to affect it - in comparison with the neoclassical model's assumption of perfect knowledge transfer. An analysis of gaps was undertaken using an interactive web-based puzzle-building activity with participants in the water sector. The primary gaps identified are not those that state actors continue to focus on in policy interventions; instead, they include the need to enable effective demand by end users, to facilitate more direct interaction between users and researchers, and to involve the private sector much more strongly in water innovation. Human capacity needs were highlighted, as was the need for strong leadership and openness in data sharing. The argument is made that those gaps that are seen as least important by practitioners and researchers in the sector are the very gaps that South African water innovation policy continues to focus on, while the gaps in cognitive capacity, in structures allowing the articulation of societal needs, and in industry involvement are largely un(der)addressed. This suggests that a linear, or neo-classical understanding of innovation may underlie innovation policy for water in South Africa. Recommendations for future policy directions include promoting knowledge-related infrastructure and data sharing; reorganising the research environment within universities; strengthening support for entrepreneurs; and creating centres of competency with strong industrialdesign and economic- and market analysis capabilities.
\end{abstract}

\section{INTRODUCTION}

Water researchers in South Africa (SA) are a small but relatively productive group who have contributed more than 3 times the country's average output of ISI-indexed (Institute for Scientific Information, now Thomson Reuters Web of Science) publications compared to all other disciplines. South Africa's contribution to published water and wastewater research is ranked $19^{\text {th }}$ in the world (Pouris, 2013). The challenge is not only to sustain this academic endeavour, but also to address current and future pressing socio-economic challenges and to enable innovation that will contribute directly to the development of a knowledge-based economy.

The knowledge-based economy is widely accepted as the direction in which world economies are moving (Journard et al., 2012; Llerena and Matt, 2005). Central to the knowledge economy is innovation: the creation or adaptation of new knowledge, technologies, processes and techniques which effect economic or social development (Diyamett, 2012; Chaminade et al., 2009; Lundvall et al., 2009). Innovation is crucial for development in two ways. It is fundamental to economic growth, industrial competitiveness, and therefore 'catchingup' with industrialised economies (Chaminade et al., 2009). Secondly, innovation can be targeted to solving or mitigating developmental problems, or 'to activities that help to create sustainable livelihoods' such as 'water management and sanitation' (Lundvall et al., 2009). Innovation in a developing country such as South Africa must therefore be understood both in terms of its impacts on macroeconomic performance and on the achievement of other developmental goals. This includes meeting social and basic needs, particularly of the poor (Cozzens and Kaplinsky, 2009).

\footnotetext{
* To whom all correspondence should be addressed.

× +27 21650 2875; e-mail: kevin.winter@uct.ac.za

Received 1 July 2014; accepted in revised from 13 March 2015
}

\section{Systemic problems in South Africa: setting the scene}

South Africa increased its investment in research and development (R\&D) from $0.73 \%$ of gross domestic product (GDP) in 2001 to a peak of $0.93 \%$ of GDP in 2008 (OECD, 2012), representing the largest increase in gross domestic expenditure on R\&D (GERD) compared to any other African country and approaching the target of $1 \%$ GERD/GDP recommended by UNESCO (2010). The latest Department of Science and Technology national survey reports that South Africa's investment in research and development (R\&D) grew to ZAR 22.2 billion in 2011/12, an increase of ZAR 2 billion over the previous year, representing $0.76 \%$ of gross GDP (DST, 2014). In comparison to other African countries, South Africa has a relatively sophisticated system of R\&D and produces nearly $50 \%$ of all scientific publications on the continent (UNESCO, 2010).

Despite the relative maturity of South Africa's R\&D system, however, several 'systemic problems' prevail (Chaminade et al., 2009). A systemic problem is defined as 'an inability of the system to support the creation, absorption, retention, use and dissemination of economically useful knowledge' (Chaminade et al., 2009 p. 57).

In 1996 the White Paper on Science and Technology (RSA, 1996) entitled 'Preparing for the 21st Century', identified seven systemic problems, namely:

- A fragmented and inadequately co-ordinated science system

- The erosion of innovative capacity

- Poor knowledge and technology flows from the science base into industry

- Poor networking both within the region and in the global context

- Low investment in $\mathrm{R} \& \mathrm{D}$

- Imbalances created by past policies and actions

- Lack of competitiveness within the global environment 
In 2002 the South African Government adopted the National Research and Development Strategy (RSA, 2002) in an attempt to address the failures identified in the White Paper. The strategy aimed to promote South Africa's competitiveness, to develop synergies among the public and private components of the science system, to develop human resources and build R\&D capacity, and to achieve an investment ratio of $1 \%$ GERD/GDP. The South African Research Chairs Initiative and the Centres of Excellence programme were among the projects established under the strategy.

Eight years later, the Department of Science and Technology's Ten-Year Innovation Plan (2008-2018) (DST, 2008), entitled 'Innovation towards a knowledge-based economy', likewise sought to address the systemic failures described previously. More recently the National Development Plan (NDP), with its overall aims of eliminating poverty and reducing inequality (RSA, 2012), includes some discussion on R\&D. The NDP identifies many of the same systemic problems, and focuses on the needs for improved higher education, strengthened human capacity, improved linkages between the needs of business and the outputs of innovation, and the need for better partnerships between government and the private sector so as to raise the level of $\mathrm{R} \& \mathrm{D}$ that is required to support a modern economy. As a forerunner to the NDP Report, the Government established a Commission to formulate a 'Diagnostic Report' (2011) to examine South Africa's achievements and shortcomings since 1994. The overriding conclusions of the report were twofold: the general failure to implement policies; and the lack of broad partnerships.

This sequence of plans and strategies, spanning nearly 20 years, highlights systemic failures in innovation in South Africa. It highlights recurring themes, namely the limited capacity to innovate; the poor flow of knowledge and technology from science to industry and business; the relatively low investment in R\&D; and a lack of competitiveness within the global environment.

\section{A CONCEPTUAL FRAMEWORK FOR INNOVATION}

In this study innovation is broadly understood as the creation or adaptation of new or existing knowledge, technologies and techniques to solve social or economic problems or bring about economic growth (Diyamett, 2012; Rose, 2012; Chaminade et al., 2009; Lundvall et al., 2009). The definition incorporates science (ordered, systematic intellectual knowledge generation) (Foray, 2004), technology (the application of this knowledge in physical artefacts and processes), and the supporting processes of commercialisation, marketing, administration and management that result in the diffusion of knowledge into society (Rose, 2012). It is different from R\&D in that it entails the diffusion and implementation, not simply the creation, of a new technology or technique. Innovation in the water sector is the generation of knowledge, the development of related technologies and their diffusion into the economy and society, meeting the needs of society and the environment.

In South Africa, as elsewhere, there is a pressing need for real breakthroughs in both the scale and quality of water and wastewater services. Thomas and Ford (2005) contend that there is a crisis of innovation within water and wastewater industries worldwide and a ubiquitously short-term view of the developmental needs in water management. Commentators have identified a 'knowledge chasm' (Pouris, 2013) in innovation in South Africa, in which researchers and society are separated by a lack of knowledge transfer and learning.
Historically, innovation has been approached in two distinct ways in theory and policy development: the market-failure or neoclassical approach, and the innovation systems approach. These two approaches offer different ways of understanding innovation in a given context, both in conceptualising problems and in determining innovation policies. The neoclassical approach, which arose in the 1960s, is based on the work of Nelson (1959) and Arrow (1962), for whom innovation is essentially a linear activity. The second approach to innovation is a more recent one in which the linear understanding of innovation is rejected (Lundvall, 1988; Freeman, 1981). Instead, innovation occurs in complex systems, which change and evolve, and are highly specific to context.

\section{The neoclassical or research-based approach}

The neoclassical model is primarily about the creation of new knowledge. Innovation is essentially a linear process: knowledge (information) is produced by scientists and researchers, communicated in codified ways, and then becomes an input for other economic activities 'downstream' (Bach and Matt, 2005). Science and technology are central, and the approach is 'based upon experimentation (typically in labs), formalization, and codification of the identified knowledge' (Lundvall, 2009). Innovative activity uses inputs, such as knowledge, to produce a particular output, such as a technology. Knowledge and technology can be reduced to information. Information is codified and generic, accessible and easily adaptable, and can be transferred without significant cost (Cohendet and Meyer-Krahmer, 2005). However the 'output' of innovation is uncertain and may take a long time to reach the market place. Both the costs and the risks of innovation are high, because of uncertainty both in the final outcome of the innovative activity and in the level of demand for the output. Once it is realised, the output might be beneficial to competitors and consumers who benefit without necessarily paying for the innovation. In economic terms, it is a non-excludable and non-rival good. The rate of return for any individual innovator is therefore too low to allow further investment, although the rest of society may benefit. This potentially reduces any incentive to innovate (Cohendet and Meyer-Krahmer, 2005), causing a situation referred to as 'market failure'. Market failure is the central tenet of the neoclassical approach as opposed to an innovation systems approach. As Chaminade et al. (2009 p.363) put it, the 'uncertainty, appropriability and indivisibility that characterise scientific knowledge will lead to an underinvestment in $\mathrm{R} \& \mathrm{D}$ by private actors, thus justifying the intervention by the government'. In order to counteract or reduce the risk of market failure, governments and state institutions typically intervene in the following ways.

The state may intervene to improve information about demand (to reduce the risk and uncertainty for innovators) or supply (to give the market better access to innovations) (Bach and Matt, 2005). It may also use what David (1993) refers to as 'the three P's': public patronage (research grants, subsidies, tax credits etc.), state procurement or production (i.e. the state carries out innovative activity, or orders innovative outputs) and the creation of intellectual property systems. Under the neoclassical framework, these policy actions are expected to improve the allocation of resources to an innovation optimum, a state of equilibrium. The neoclassical approach is criticised because its linear concept of innovation causes an overemphasis on R\&D while ignoring the uncertainties associated with the process (Chaminade, 2009). 


\section{The innovation systems approach}

The innovation systems (IS) approach arose in response to some of the problems identified within the neoclassical framework, particularly in its empirical applications. The central tenet of the IS approach is of course the conceptualisation of innovation as a system and not a linear process.

Innovation systems comprise individual actors and organisations which bring about innovation through their relationships with one another. Innovation is not, in this approach, something which an individual accomplishes alone if given the right inputs of skills, investment and incentive. Rather, innovation incorporates both traditional R\&D activities and the diffusion of technologies through society, and all of the factors which influence these (Rose, 2012). In addition, knowledge is seen as having both transferable and tacit dimensions because it is not necessarily easily or wholly transferable. Learning, whether by individuals or organisations, becomes an important process in an innovation system. Knowledge and learning, in this framework, may increasingly be in the form that is envisioned as 'Mode 2': that is, distributed, context-specific and democratised (Gibbons et al., 1994) and taking place in a society that is increasingly 'knowledge-oriented' (Cohendet and Meyer-Krahmer, 2005), where the diffusion of knowledge is supported by information technology and the growth of service industries.

Unlike the neoclassical approach, the innovation systems framework does not envision any kind of 'optimum' state of innovation. Instead, the system is in constant evolution which follows some form of trajectory (Bach and Matt, 2005). Although there is no optimality, it is sometimes possible to assess whether one situation is preferable to another, based on actual outcomes rather than forecasts. The state's role, in contrast to the relatively simple 'three P's', is more nuanced and focused on addressing specific systemic problems. The basic principle of state involvement is to aid the development of learning capacity on the part of organisations and individuals, and to provide conditions that are conducive to the use of this capacity in innovative activity (Bach and Matt, 2005). Different policy actions adapted to the context and applied in an experimental and adaptive manner are required (Chaminade, 2009). They may include the promotion of knowledge-related infrastructure, provision of support to communities of knowledge, reinforcement and adaptation of the education system, adaptation of the property rights system to take into account the nature of knowledge, and support for infant enterprises (Bach and Matt, 2005).

The most significant challenge with the innovation systems framework is its application to the developing world. It assumes an established innovation system, having arisen largely in the context of the strong market economies of Europe, North America and Japan. Weaknesses in developing contexts include a lack of clearcut market mechanisms for consumers to express their innovation needs, coupled with poor innovation infrastructure and low levels of education and income (Diyamett, 2012). Thus, an innovation systems analysis of developing countries must take into account a 'systems building' approach as well as an analysis of what already exists (Pant and Hambly-Odame, 2012).

\section{Choosing an approach: neoclassical and innovation systems}

The neoclassical approach offers a high level of internal coherence and inherent linear logic, and has been the dominant framework for several decades (Bach and Matt, 2005). Science and innovation policies largely emphasise linear relationships between science and society (Pant and Hambly-Odame, 2012). As a result, the focus of traditional research, technology and development policies has been on the 'conditions of production of new knowledge, and not on the ways that the knowledge is assimilated and diffused through society' (Cohendet and Meyer-Krahmer, 2005). Under the neoclassical framework, knowledge is assumed to be easily assimilated without significant costs, but this can lead to a restricted and restrictive understanding of knowledge since it reduces knowledge to mere information while ignoring its tacit, cumulative, pathdependent and contextual aspects (Cohendet and MeyerKrahmer, 2005). 'Knowledge has a unique property' in that 'it always and only exists in the minds of individuals' (Metcalfe, 2005). Thus, all knowledge is tacit and its codification is only ever an imperfect public representation. It follows that the neoclassical understanding of knowledge is flawed since knowledge cannot be entirely freely or perfectly transmitted, it cannot be either entirely non-rival or entirely non-excludable. Thus, the notion of market failure, which rests upon an understanding of knowledge as instantaneously and completely shared, is limited (Metcalfe, 2005). In contrast, the innovation systems framework views knowledge as tacit and imperfectly transferred, thereby highlighting the role of learning as vital to innovation. Therefore it has a much broader scope than the neoclassical framework, by addressing problems of assimilation and diffusion of innovations in addition to problems of knowledge creation.

The linear logic of the neoclassical framework is appealing - science 'pushes' and the market 'pulls', and physical resources (particularly their allocation) are the crucial factor for innovation. However this is simplistic, especially given the flaws in the market-failure basis of the framework. It also tends to downplay the specific institutional frameworks in which innovative activities take place (Chaminade, 2009). It is for these reasons that Metcalfe (2005) argues that the 'market-failure framework', despite its formal elegance, is an empty box. It also explains why the innovation systems framework emerged in response to some of problems (Chaminade, 2009). In theory, there is an apparent consensus around the need for a systems approach to innovation policy. In most cases, however, the neoclassical framework is dominant in practice.

\section{Bridging the gaps}

An innovation system is usually described by analysing either its components (the organisations and institutions involved), its functions (such as R\&D, the creation of new knowledge, competence building, formation of new product markets, creation and change of organisations, networking, and incubating activities) or its processes (learning, competence-building, and selection). However, innovation systems are highly contextual and, in an innovation systems framework, there is no 'optimal state' with which to compare a given system (Bach and Matt, 2005). Analysis of a given system, therefore, must have reference to the system failures or 'gaps' that hinder the innovation process in that system. It cannot be achieved by direct comparison with other systems or a theoretical checklist of some kind. Lorentzen (2012) argues that 'it is important to understand which part of the system is dysfunctional or inert, thus holding back overall system performance.' Analysing an innovation system requires a discussion of 'failures' in the system - gaps and problems that hinder or prevent effective innovation (Cohendet and Meyer-Krahmer, 2005). 


\section{Gaps}

Central to innovation policy is the notion of 'system failures' (Chaminade, 2009). The terminology of 'failures' is adopted by many authors for simplicity, but in the context of this study it is equally appropriate to use the terms 'gaps' or 'holes' (Bach and Matt, 2005). 'Failure' implies a 'mythical optimum' against which to compare an actual system. Thus gaps are classified as relating to the components or the functioning of the system (Bach and Matt, 2005) or relating to the process of innovation.

Component gaps could relate to a deficiency in certain types of organisations (for instance, in research institutions or in infrastructure) or to a deficiency of competences within organisations - human, organisational or technological reflected in a limited capacity to learn (Chaminade et al., 2009). They also include 'network problems', or the failure to engage in interactive learning. Potential component gaps arise from a lack of coordination between different agents and groups of agents, or a lack of appropriate institutions to allow for collective creation of knowledge (Bach and Matt, 2005). Gaps in system dynamics are more difficult to describe or analyse because they relate to problems of transition through or between paradigms, and are caused by a lack of sufficient capabilities on the part of system actors or by poor selection processes in which organisations or technologies are maintained too long or eliminated too rapidly. Bach and Matt (2005) identify two other forms of gap: gaps in knowledge processing which are connected to institutional problems in codifying knowledge and transfer between organisations; and gaps caused by exploitation or exploration failures, essentially the failure to dedicate resources to the right innovative efforts.

Chaminade et al. (2009) acknowledge that innovation systems in developing countries may face different challenges. They suggest that innovation systems in less developed economies should be conceptualised as emerging and in a state of development, because only some of the 'building blocks' are in place and interactions between elements are still in formation. The 'gaps' discussed above offer a useful way in which to analyse an innovation system, and will be used in this study as a point of reference in the analysis of the innovation system for water in South Africa.

\section{METHODS}

\section{Measuring innovation}

$\mathrm{R} \& \mathrm{D}$ indicators of financial and human resource inputs, as a common proxy for the measurement of innovation (OCED, 2002; 2012), provide a limited picture of South Africa's innovation system for water. They are based largely upon a linear understanding of innovation reminiscent of the neoclassical model discussed above. Their primary usefulness is in their standardisation and comparability across countries and systems: in addressing the particular gaps in a given sectoral innovation system, they address one aspect only of a complex system. In this study, we utilised a more conceptual approach, based upon the innovation systems model.

\section{'Gaps puzzle' tool: perceptions of gaps}

The interactive web-based 'gaps puzzle' tool was designed and built to create an understanding of the systemic aspects of the innovation system. In particular, the tool aimed to elicit an understanding of the players or actors involved in an innovation system; the practices or functions of innovation; and the impacts and outcomes of innovation. Such an understanding cannot be gleaned from written policy alone - as Mani (2004) notes of South Africa, 'considerable sophistication in innovation policy formation' does not translate to an effective innovation system. Neither can an understanding be gained from analysis of R\&D statistics alone, which give (at best) a numerical 'snapshot' of actors and certain linkages between them. An understanding of systemic failures requires a broader-based approach, including the perspectives of actors themselves.

The initial specifications for the tool used in this study were developed in collaboration with three expert reference groups, including participants from national, provincial, and local government, from higher education, and from the Water Research Commission. Dubbed the 'gaps puzzle', the tool took the form of a simple game requiring the placement of building blocks onto a grid. Participants chose building blocks bearing descriptors of different aspects of the innovation system, under the overarching categories of 'players', 'practices', and 'outcomes'. They then placed the blocks into a grid, choosing the appropriate row based on importance or desirability for a strong innovation system. Once a block was placed, participants chose a colour (green, yellow or red) based upon the perceived current state of that innovation system. Apart from choosing predefined blocks, participants could also create their own. The tool was designed to be interactive and intuitive; a simple bar graph gave instant feedback on the choices made by participants so that they could immeditately see the consequences of their choices. In this way, two simple pieces of information were obtained about each aspect of the innovation system: its importance (in an ideal state) and its strength (in a current state). The combination of these two factors, it is argued, gives a conceptual and qualitative understanding of systemic gaps in SA's innovation system for water.

This tool was hosted online and web links were distributed to a database of 836 individuals in the water sector in SA, compiled in an earlier study (Siebrits et al., 2014). The use of the tool was approved by the University of Cape Town's Science Faculty Ethics Committee. It was piloted with a small reference group, who gave critical feedback, before being administered for a limited period of 10 days with the full set of recipients. A full list of the building blocks from which participants chose is given in Tables 1 to 3 .

Results from the tool were collected in an online database. No connection was made between the participant's identity and their submission, although participants were asked to identify the sector in which they worked (public, private, NGO, or education), and how many years of experience they had in the water sector. Based on the choice of the row in which a particular block was placed, a numerical weighting was assigned to that block - see Table 4. Colour choices were also weighted - see Table 5 . The weightings assigned to each block were used to calculate average levels of importance and effectiveness (players and practices) and of desirability and nearness (outcomes), across the entire sample. Blocks selected by less than $5 \%$ of the sample were ignored, to correct for the potentially skewing effect of only a few participants selecting a particular block. Relative 'scores' of gaps were calculated by multiplying the (non-weighted) averages of importance and effectiveness by one another. A block ranked as 'most important' and 'very effective' would have a low gap score in comparison with one ranked 'most important' and 'ineffective'. In contrast, a block ranked as 'less important' and 'effective' would have a low gap score. This allowed for an overall ranking of gaps as identified by participants. 


\begin{tabular}{|l|l|}
\hline \multicolumn{2}{|c|}{$\begin{array}{c}\text { Table 1 } \\
\text { Players building blocks }\end{array}$} \\
\hline Broad categorisation & Building blocks \\
\hline Individual researchers & Researchers, champions, citizens \\
\hline Research groupings & Research alliances, centres of excellence, innovation hubs, research units, NGOs, end users \\
\hline Research support & Government officials, citizens, politicians, research support teams, sponsors, mentors \\
\hline Research marketers & Marketers \\
\hline Knowledge creators & Academics \\
\hline Product developers & Business, industry, entrepreneurs \\
\hline
\end{tabular}

\begin{tabular}{|l|l|}
\hline \multicolumn{2}{|l}{} \\
Practices building blocks \\
\hline Broad categorisation & Building blocks \\
\hline Funding support & Financial support, returns of research investments, incentivised funding \\
\hline Education \& training & Leadership, appropriate curriculum, student bursaries \\
\hline Strategic research & Commissioned research, setting priorities \\
\hline Needs focus & Research for implementation, applied research, responding to national strategies \\
\hline Human capacity & Strengthening human capacity, building research skills \\
\hline Institutional support & Data sharing, providing real world space for research, incentives, \\
\hline Relationships & $\begin{array}{l}\text { Consortiums, creating centres of excellence, marketing of research products, peer review processes, build- } \\
\text { ing research alliances, inclusion of citizen science, public relations and marketing }\end{array}$ \\
\hline
\end{tabular}

\begin{tabular}{|l|l|}
\hline \multicolumn{2}{|l}{ Outcomes building blocks } \\
\hline Broad categorisation & Building blocks \\
\hline Knowledge diffusion & Knowledge management, communication of knowledge, Information about research \\
\hline Knowledge impact & Research exemplars, use and value of research \\
\hline Knowledge creation & Knowledge generation \\
\hline Intangible assets & $\begin{array}{l}\text { Job creation, informing decision making, strengthening human capacity, encouraging curiosity, desire to } \\
\text { learn more }\end{array}$ \\
\hline Creative creating goods \& services & Commercialisation of research products, achieving efficient funding models \\
\hline Alignment with national agenda & $\begin{array}{l}\text { Improving economy, contributing to development, research for sustainability, improving livelihoods, bet- } \\
\text { terment of society }\end{array}$ \\
\hline
\end{tabular}

\begin{tabular}{|l|l|l|l|l|}
\hline \multicolumn{7}{|c|}{ Teightings assigned to row choices in the ‘Gaps' web tool } \\
\hline Row & Weighting & Players label & Practices label & Outcomes label \\
\hline Top & 4 & Most important & Most important & Most desirable \\
\hline $2^{\text {nd }}$ & 3 & Very Important & Very Important & Very Desirable \\
\hline $3^{\text {rd }}$ & 2 & Important & Important & Desirable \\
\hline Bottom & 1 & Less Important & Less Important & Less Desirable \\
\hline
\end{tabular}

\begin{tabular}{|l|l|l|l|l|}
\hline \multicolumn{5}{|c|}{ Weightings assigned to colour choices in the 'Gaps' web tool } \\
\hline Colour & Weighting & Players label & Practices label & Outcomes label \\
\hline Red & 2 & Ineffective & Ineffective & Very far \\
\hline Yellow & 1 & Not very effective & Not very effective & Not very close \\
\hline Light green & 0.5 & Effective & Effective & Close \\
\hline Dark green & 0 & Very effective & Very effective & Very close \\
\hline
\end{tabular}




\section{Identifying the gaps}

The 'gaps puzzle' web tool had a response rate of 134 individuals, or $16 \%$. Nearly $50 \%$ of the respondents had between 0 and 5 years' experience in the water sector, with $42 \%(n=57)$ being in the private sector; $32 \%(n=43)$ from higher education institutions; $21 \%(n=29)$ from the public sector; and slightly fewer than $4 \%(n=5)$ from non-governmental or community-based organisations (NGOs or CBOs).

\section{Players: actors within the system}

In total 19 items were identified as possible gaps in the 'Players' category (Fig. 1). The largest gaps in 'Players' were identified as 'Government officials' and 'Politicians'. The high importance ranking given to politicians and government officials was contrasted with a low effectiveness ranking of these same actors. 'End users' constituted the next greatest gap, followed by actors in industry and private citizens. The smallest gaps were in 'Research support teams', 'Research units', Centres of Excellence and 'Researchers'. The perceptions offered by the respondents suggest that the obvious 'actors' within an innovation system are already in place (e.g. researchers, research units, Centres of Excellence), but there are gaps in national leadership, political will, and consideration of the needs of end-users, and limited partnerships between industry and research activity. The limited contribution or involvement of citizens was identified as problematic by all four sectors represented in the database (i.e. education, NGO, private and public sector respondents).

\section{Practices}

The largest gaps in 'Practices', where items of high importance contrasted with low effectiveness, were perceived as 'Leadership' and 'Strengthening human capacity', (Fig. 2). These two gaps received the strongest support from the public and private sectors. 'Data sharing' constituted the next greatest gap, followed by 'Public relations'. The smallest gaps, conversely, related to 'Study incentives' and 'Student bursaries', 'Centres of Excellence', 'Research alliances', and 'Commissioned research'.

\section{Outcomes}

The ranking of blocks relating to 'Outcomes' was according to desirability and nearness rather than importance and effectiveness. The largest gaps in 'Outcomes' were in 'Improving livelihoods' and in 'Job creation' (Fig. 3). 'Economic improvement' constituted the next greatest gap in 'Outcomes', followed by 'Societal benefits' and 'Sustainability'. The smallest perceived gaps included 'Knowledge generation' and 'Information about research'.

\section{DISCUSSION}

Annual reports and strategic plans available for the NRF (2008), DST (2014), WRC (2012) and TIA (2012) suggest that the language of innovation systems has taken firm root in South African policy. References to innovation and to national systems of innovation (NSI) abound, and much of the terminology used is reminiscent of OECD publications. Indeed, the 2002 Research and Development Strategy builds upon the NSI concept in critiquing policy and setting strategic directions. The DST's Ten Year Innovation Plan (2008) similarly draws on innovation systems concepts, describing the NSI as 'central to the country's prospects for continued economic growth and socioeconomic development'.

What is unclear, however, is whether this constitutes a real shift in policy, or simply an alternative set of descriptions for very similar activities. Mani (2003) argues that the innovation

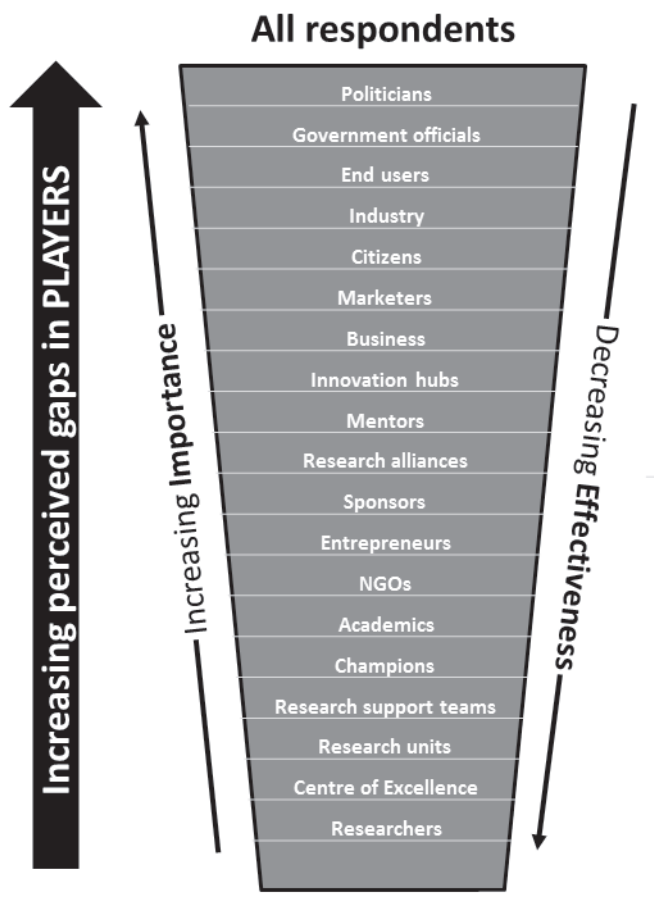

\section{Top six gaps by respondent sector}

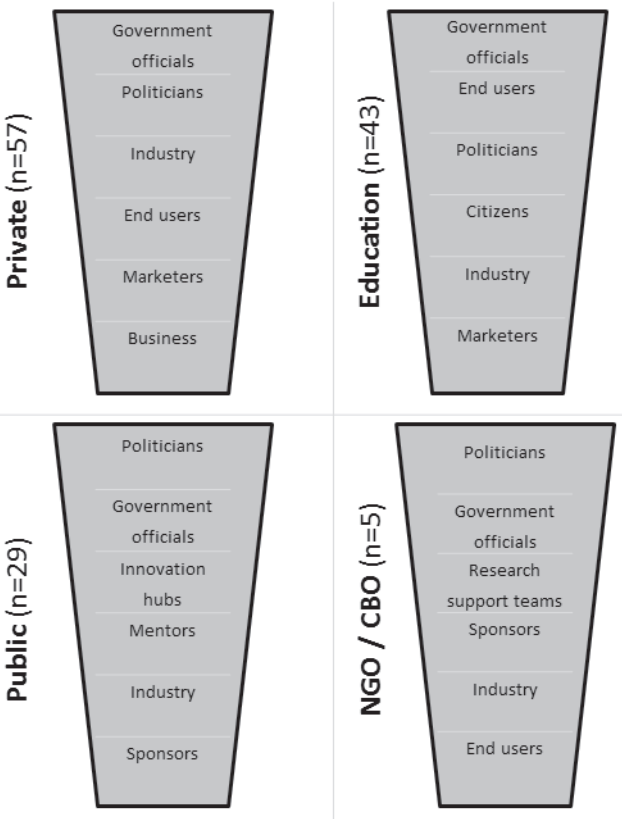

Figure 1

Ranked gaps in the Players category. The leftmost graphic shows the overall ranking of the 19 gaps selected by more than $5 \%$ of the sample. The graphics on the right show the top-ranked ('biggest') gaps from each of the four respondent sectors. 


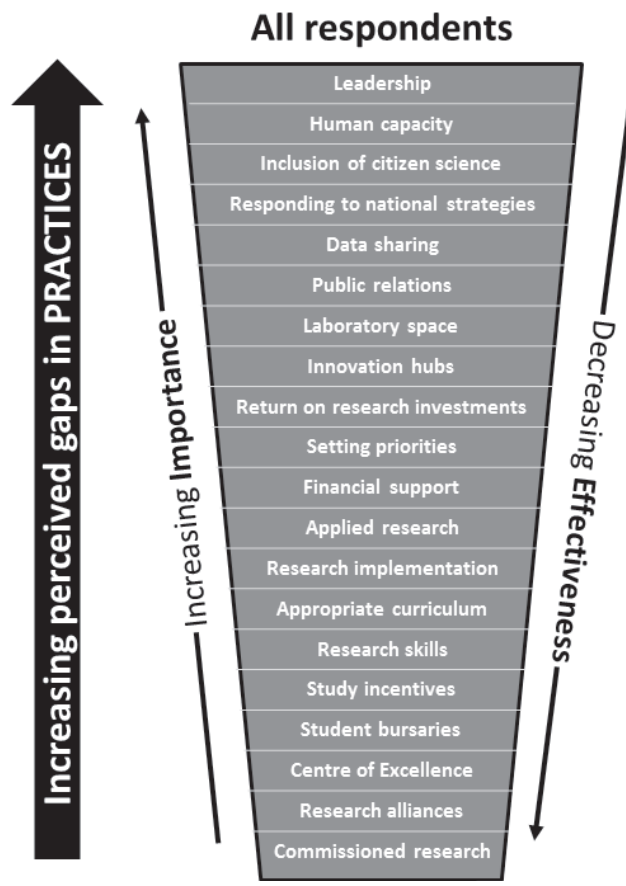

\section{Top six gaps by respondent sector}
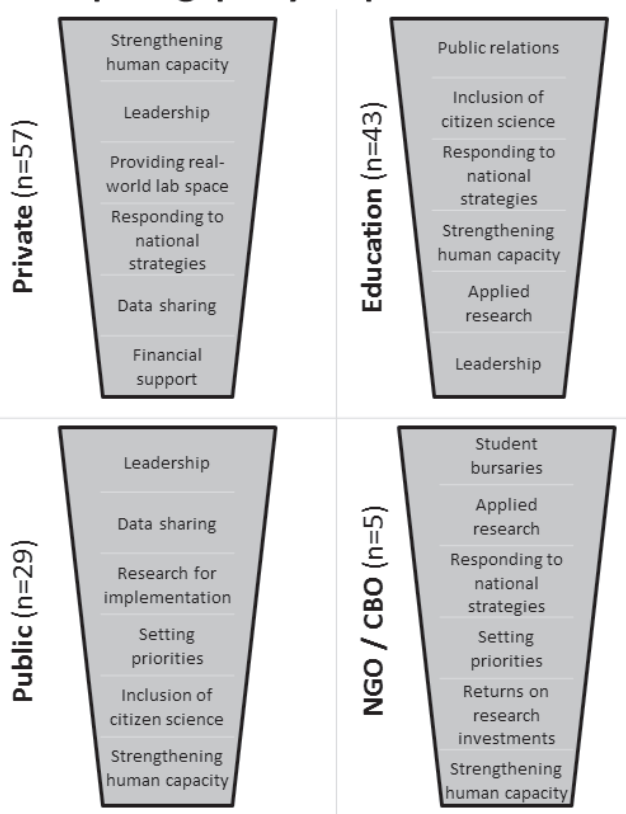

Figure 2

Ranked gaps in the 'Practices' category. The leftmost graphic shows the overall ranking of the 20 gaps selected by more than $5 \%$ of the sample. The graphics on the right show the top-ranked ('biggest') gaps from each of the four respondent sectors.
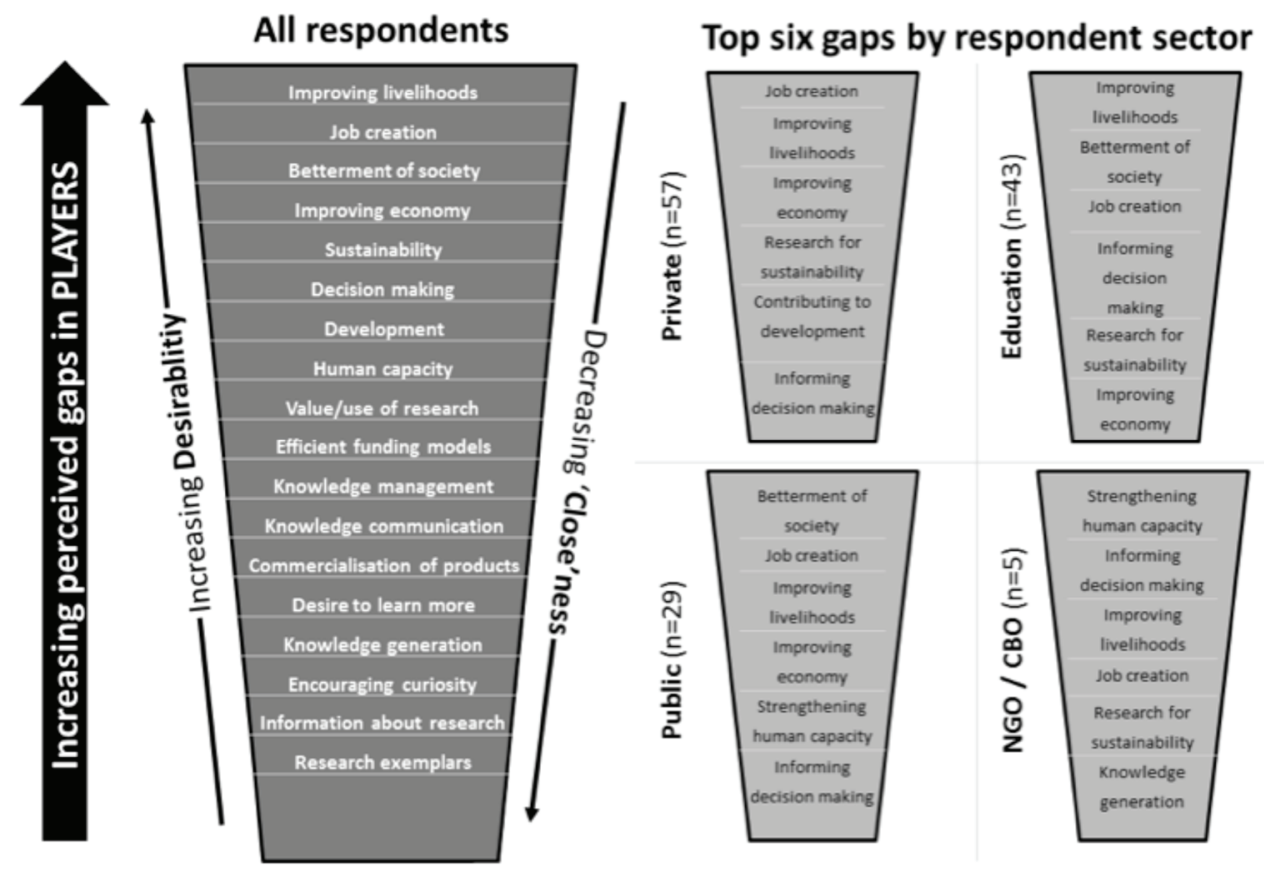

Figure 3

Ranked gaps in the 'Outcomes' category. The leftmost graphic shows the overall ranking of the 18 gaps selected by more than $5 \%$ of the sample. The graphics on the right show the top-ranked ('biggest') gaps from each of the four respondent sectors.

systems approach in South Africa exists 'more in form than in content'. Although many institutional changes have occurred since Mani's analysis, not least in the wake of the OECD's peer review of the South African Innovation System in 2006 (DST, 2012), it is an argument that bears closer analysis, particularly in a sector-specific context. The data and views gathered in the course of this study enable an analysis of challenges to water innovation in South Africa, and of gaps in the innovation system for water. 


\begin{tabular}{|l|l|}
\hline \multicolumn{2}{|c|}{ Edquist's (2004) innovation system functions and SA organisations } \\
\hline Function (Edquist, 2004) & Component \\
\hline Research and development; the creation of new knowledge & $\begin{array}{l}\text { CSIR, HSRC, Higher education institutions, consultancies, industry } \\
\text { R\&D divisions }\end{array}$ \\
\hline $\begin{array}{l}\text { Competence building; education and training, human capital } \\
\text { development }\end{array}$ & WRC, NRF, DST, DHET \\
\hline Formation of new product markets & \\
\hline Articulation of user needs & DST (possibly) \\
\hline Creation and change of organisations & NRF Centres of Excellence / Research chairs \\
\hline Networking around knowledge & DST (possibly) \\
\hline Creation and change of institutions & TIA (possibly) \\
\hline Incubating activities & WRC, NRF, CSIR \\
\hline Financing of innovation & CSIR, private consultancies \\
\hline Consultancy services & \\
\hline
\end{tabular}

\section{Actors}

Rose (2012) suggests that in an innovation system framework, innovation is influenced by many more players and organisations than just the traditional research institutions. Participants in the 'gaps puzzle' confirmed this in identifying government officials, politicians, end users, industry, and citizens as the most significant 'Players' gaps. As seen in Table 7, traditional S\&T players are positioned at the bottom of the list of identified gaps. Instead, it is those involved in the governance of innovation who are singled out as most ineffective and responsible for limiting the development of innovation, followed by the end user and citizen, whose effectiveness in promoting innovation may be retarded by the 'poor market mechanisms' as described earlier by Diyamett (2012). The next-largest gap in players is amongst business and industry: limited effectiveness in innovation amongst this group may result from isolation and a lack of formal and informal networks of knowledge diffusion and support (Metcalfe, 2005).

\section{Practices}

The greatest gap in 'Practices' was identified as the strengthening of human capacity (see Table 8). Vital to any innovation system is the level of 'cognitive capacity' (Bach and Matt, 2005) its actors are able to muster. Strong human capacity is needed in order to implement knowledge generated elsewhere. Linked to both formal educational modes of learning and to 'DoingUsing-Interacting' (Cozzens and Kaplinsky, 2009) learning, levels of learning capacity determine how well knowledge is able to diffuse and be utilised, and thus the level of innovative activity that is possible. The greatest gap is also recognised as leadership. Though not elaborated on by participants, leadership is assumed to entail both strategic-direction and innovative-practice aspects. In the absence of a strong end-user voice in determining the direction of innovation, strong and visionary leadership becomes increasingly important. Data sharing was identified as another important gap in practices in SA, data collected by public sector institutions is stored and maintained in separate, non-compatible databases. In some cases, as for instance the South African Weather Service, the organisation may charge fees for access to the data, even to other public institutions. This kind of practice may be one of the reasons why participants stressed the gap in data sharing.
Again, traditional research-oriented practices find their place at the bottom of the list; and peer review processes, research alliance building, and student bursaries are areas with little to no gap. These practices, however, are areas on which the WRC and NRF concentrate much of their effort.

\section{Outcomes}

The four greatest gaps identified in desirable outcomes of innovation are interrelated - improving livelihoods, creating jobs, improving the economy, and bettering/improvements for society. These are the ultimate outcomes of any well-functioning innovation system and have particular relevance in SA's developing context. Research for sustainability, the next-largest gap, has resonance with what Thomas and Ford (2005) termed a crisis in innovation for water - the need for technologies and techniques for sustainable use of water resources is pressing. Once more, the traditional targets of interventions - knowledge generation and the provision of information about research are ranked as the least important of the identified gaps in the innovation system.

\section{Functions and processes}

In terms of the innovation system functions described by Edquist (2004), the water innovation system in SA has gaps in many major respects, not least within formal organisations. Table 6 shows the organisational components of the innovation system, aligned with their key mandated functions.

Description of the organisations involved in the SA innovation systems for water without discussing the way they relate to one another is an unsatisfactory endeavour. At least as important are the linkages between organisations - the practices, rules, laws, habits, and routines regulating interaction between organisations. These linkages are referred to as institutions in the IS literature and include the practices, rules, laws, habits, and routines regulating interaction between actors.

The gaps and challenges identified thus far suggest that policy for water innovation in SA is seen largely as a problem of optimising traditional science and technology, or R\&D. Beyond the creditable inclusion of human capacity development in strategic actions, water innovation is treated as a linear process relying upon improved inputs to ensure the generation and use of societally relevant knowledge and technology. In 
broad outline, this corresponds to the neoclassical model of innovation policy: linear, R\&D focused, and confined to traditional research partners. Although nationally there are efforts to build a strong system of innovation, much of the actual policy action does little more than pay lip service to innovation systems thinking, relying upon traditional, R\&D-based action in practice. The gaps seen as least significant by participants in the 'gaps puzzle' are also the areas of focus of many of the strategy documents for the DST, WRC and other government organisations. There is a disconnect between what researchers and practitioners see as important gaps in the sector and what innovation policies and policy-makers seek to address in SA. The underlying assumptions of actions focused on financing $\mathrm{R} \& \mathrm{D}$, on disseminating information about science to the public, and on linkage-building between traditional partners, are the assumptions that knowledge is easily transferable and that innovation is linear and characterised essentially by market failure. They are the assumptions, in other words, of the neoclassical paradigm of innovation thinking. The real gaps in the innovation systems for water in SA, as identified by practitioners and researchers in the sector, are consistent with innovation systems theory; they relate to a far broader set of actors than the neoclassical approach encompasses and include a very different set of practices than traditional R\&D. The desired outcomes are not simply the production of knowledge, but the meeting of society's needs, development and sustainability. Filling these gaps will require a different policy approach, which complements the emphasis placed on science and technology in the past.

\section{CONCLUSION}

South Africa's expenditure in R\&D has increased significantly since 2001. Recent reports indicate a consistent investment of $0.76 \%$ of GDP in R\&D over the last 3 years, largely by public funding (45.4\%) in 2012/13, while the business sector funded $38.3 \%$ in the same period (DST, 2014). Furthermore, the Ten-Year Innovation Plan (DST, 2008) and the National Development Plan (RSA, 2012), signal a national intent to build R\&D policies, to improve investments that will meet the 'grand challenges' facing the country and to grow the knowledge economy. Scientometric evidence shows that South African researchers are actively engaged in the generation of a diverse range of knowledge in water-related fields, whose collective contribution to water knowledge ranks $19^{\text {th }}$ in the world (Pouris, 2013).

Nevertheless, evidence from this research suggests that current innovation policies are not yet effective in changing practices, outcomes and impacts on the knowledge economy, and in meeting the developmental agenda. The gap between the intentions of forward-thinking innovation policy and the realities confronting research and researchers is wide, and remains a significant challenge. Efforts to build a system of innovation are clear, but actual policy action does little to encourage innovation systems thinking, but rather relies on traditional, $\mathrm{R} \& \mathrm{D}$-based action in practice. Local government and other state players fail to create an enabling environment to test, pilot and diffuse new water-related solutions. In response, a new level of stimulation is required from the major players in the innovation system - the NRF, TIA, WRC and DST - that need to stimulate the coordination and alignment of their actions within an acceptable and appropriate innovation systems framework. The challenge could easily overwhelm current resources and capacity, particularly since the development of a progressive innovation programme continues to be distorted by Apartheid legacies and the inability of various government institutions to create an environment for the development of learning capacity and skills required to support an innovation system.

The course of action is to strengthen and rethink more innovative ways to determine needs, co-ordinate activities, build better linkages between researchers, business, industry and end-users, and actively seek opportunities to co-fund research options. It requires policy to be directed at strengthening the entire innovation chain from conceptual stage to market, while at the same time meeting social development needs. None of this innovative potential takes place without enabling and supporting strong leadership and risk-taking in water science and technology. The implications of our study suggest that major needs for the water sector include: the promotion of knowledge-related infrastructure and data sharing; a reorganization of the research environment within universities; strengthening funding for entrepreneurship and support for infant enterprises; creating centres of competency with strong industrial-design and economic- and market analysis capabilities; and the retention of post-doctoral students through improved and longer-term funding to sustain longer-term research activities.

\section{ACKNOWLEDGEMENTS}

This publication was based on the Water Research Commission administered project K5/2258 which was funded by the Department of Science and Technology. The project leaders are grateful for the contributions of the reference group members; to those who participated in small group discussions; and to those who willingly participated in the surveys. The authors are grateful for the recommendations made by the three reviewers.

\section{REFERENCES}

ARROW KJ (1962) Economic Welfare and the Allocation of Resources for Invention, the Rate and Direction of Incentive Activity. Princeton University Press, Princeton.

BACH L and MATT M (2005) From economic foundations to S\&T policy tools: a comparative analysis of the dominant paradigms. In: Llerena P and Matt M (eds) Innovation Policy in a Knowledge-Based Economy (1 $1^{\text {st }}$ edn). Springer, Berlin. 17-46.

CHAMINADE C, LUNDVALL B, VANG J and JOSEPH KJ (2009) Designing innovation policies for development: towards a systemic experimentation-based approach. In: Lundvall B, Vang J, Joseph KJ and Chaminade C (ed.) Handbook of Innovation Systems and Developing Countries. Edward Elgar, Cheltenham. 360-379.

COHENDET P and MEYER-KRAHMER F (2005) Technology policy in the knowledge-based economy. In: Llerena P and Matt M (ed.) Innovation Policy in a Knowledge-Based Economy. Springer, Berlin. 75-112.

COZZENS SE and KAPLINSKY R (2009) Innovation, poverty and inequality: cause, coincidence, or co-evolution. In: Lundvall B, Vang J, Joseph KJ, Chaminade C (ed.) Handbook of Innovation Systems and Developing Countries. Edward Elgar, Cheltenham. 57-83.

DAVID P (1993) Intellectual property institutions and the panda's thumb: Patents, copyrights, and trade secrets in economic theory and history. In: Wallerstein M, Mogee M and Schoen R (ed.) Global Dimensions of Intellectual Property Rights in Science and Technology. National Academy Press, Washington, DC.

DIYAMETT BD (2012) Building systems of innovation in an African setting: the cluster initiative development approach. In: Muchie $\mathrm{M}$ and Baskaran A (ed.) Challenges of African Transformation: Exploring through Innovation Approach. Africa Institute of South Africa / Institute for Economic Research on Innovation, Pretoria. $129-148$. 
DST (DEPARTMENT OF SCIENCE AND TECHNOLOGY, SOUTH AFRICA) (2008) Ten-Year Innovation Plan of the Department of Science and Technology. DST, Pretoria.

DST (DEPARTMENT OF SCIENCE AND TECHNOLOGY, SOUTH AFRICA) (2012) Final Report of the Department of Science and Technology Ministerial Review Committee on the Science, Technology and Innovation Landscape in South Africa. DST, Pretoria.

DST (DEPARTMENT OF SCIENCE AND TECHNOLOGY, SOUTH AFRICA) (2014) South African national survey of research and experimental development: Statistical Report 2012/13. DST, Pretoria.

EDQUIST C (2004) Systems of innovation: perspectives and challenges. In: Fagerberg J, Nelson R and Mowery D (eds) The Oxford Handbook of Innovation. Oxford University Press, Oxford. 181-208.

FORAY D (2004) Economics of Knowledge. Massacheusetts Institute of Technology, Cambridge, MA.

FREEMAN C (ed.) (1981) Technological Innovation and National Economic Performance. Aalborg University Press, Aalborg.

GIBBONS M, LIMOGES C, NOWONTNY H, SCHWARTZMAN S, SCOTT P and TROW M (1994) The New Production of Knowledge. Sage, London.

JACOBS IM, POURIS A and NAIDOO D (2014) Scientometric examination of the performance of water research in South Africa. Water SA 40 (4) 631-639.

JOURMARD R and BOUGHEDAOUI M (2012) Research typology and knowledge needs for development in Africa. In: Muchie M and Baskaran A (ed.) Creating Systems of Innovation in Africa: Country Case Studies ( $1^{\text {st }}$ edn). Africa Institute of South Africa / Institute for Economic Research on Innovation, Pretoria. 1-20.

LLERENA P and MATT M (2005) Innovation Policy in a KnowledgeBased Economy ( $1^{\text {st }}$ edn). Springer, Berlin.

LORENTZEN J (2012) Ghana's innovation system: what's wrong with it, and why. In: Muchie M and Baskaran A (eds) Creating Systems of Innovation in Africa: Country Case Studies (1st edn). Africa Institute of South Africa / Institute for Economic Research on Innovation, Pretoria. 21-45.

LUNDVALL B (1988) Innovation as inter-active process: from userproducer interaction to the national system of innovation. In: Dosi G, Freeman C, Nelson R, Silverber G and Soete L (eds) Technical Change and Economic Theory. Pinter, London. 349-369.

LUNDVALL B, VANG J, JOSEPH KJ and CHAMINADE C (2009) Innovation system research and developing countries. In: Lundvall B, Vang J, Joseph KJ and Chaminade C (eds) Handbook of Innovation Systems and Developing Countries. Edward Elgar, Cheltenham. 1-32.

MANI S (2004) Government, innovation and technology policy: an international comparative analysis. International Journal of Technology and Globalisation $129-44$.

METCALFE JS (2005) Systems failure and the case for innovation policy. In: Llerena P and Matt M (ed.) Innovation Policy in a Knowledge-Based Economy. Springer, Berlin. 47-74.

NELSON RR (1959) The simple economics of basic scientific research. I. Polit. Econ. 67 323-348.

NRF (NATIONAL RESEARHC FOUNDATION, SOUTH AFRICA) (2008) Strategic Plan of the National Research Foundation: NRF
Vision 2015. URL: http://www.nrf.ac.za/sites/default/files/documents/NRF\%20Vision\%202015.pdf (Accessed 15 June 2013).

OECD (ORGANISATION FOR ECONOMIC CO-OPERATION AND DEVELOPMENT) (2002) Frascati Manual 2002: Proposed standard practice for surveys on research and experimental development. The measurement of scientific and technological activities. OECD, Paris. URL: http://www.oecd.org/science/inno/frascatimanualproposedstandardpracticeforsurveysonresearchandexperimentaldevelopment6thedition.htm (Accessed 15 June 2013).

OECD (ORGANISATION FOR ECONOMIC CO-OPERATION AND DEVELOPMENT) (2012) Measuring R\&D in developing countries: Annex to the Frascati Manual. URL: http://www.oecd.org/science/ inno/49793555.pdf (Accessed 15 June 2013).

OECD (ORGANISATION FOR ECONOMIC CO-OPERATION AND DEVELOPMENT) (2012) Science and innovation: South Africa. In: OECD Science, Technology and Industry Outlook 2012. OECD, Paris.

PANT LP and HAMBLY-ODAM H (2012) Innovations systems in renewable natural resource management and sustainable agriculture. In: Muchie M and Baskaran A (ed.) Challenges of African Transformation: Exploring Through Innovation Approach. Africa Institute of South Africa / Institute for Economic Research on Innovation, Pretoria. 52-79.

POURIS A (2013) A pulse study on the state of water research and development in South Africa. WRC Report No. 2199/1/12. Water Research Commission, Pretoria. ISBN 987-1-4312-0370-3.

ROSE K (2012) Enhancing innovation in developing country systems: A synthesis of case studies and lessons from Uganda. In: Muchie M And Baskaran A (Eds) Creating Systems of Innovation in Africa: Country Case Studies ( $1^{\text {st }}$ edn). Africa Institute of South Africa / Institute for Economic Research on Innovation, Pretoria. 78-96.

RSA (REPUBLIC OF SOUTH AFRICA) (1996) White Paper on Science and Technology. Government Printer, Pretoria.

RSA (REPUBLIC OF SOUTH AFRICA) (2002) South Africa's National Research and Development Strategy. Government Printer, Pretoria.

RSA (REPUBLIC OF SOUTH AFRICA) (2012) National Development Plan: Vision for 2030. Government Printer, Pretoria.

SIEBRITS R, WINTER K, BARNES J, DENT MC, EKAMA G, GINSTER G, HARRISON J, JACKSON B, JACOBS I, JORDAAN A, KASAN HC, KLOPPERS W, LE ROUX R, MAREE J, MOMBA MNB, MUNNIK AV, O'KEEFFE J, SCHULZE R, SILBERBAUER M, STILL D and VAN ZYL JE (2014) Priority water research questions for South Africa developed through participatory processes. Water SA 40 (2) 199-210.

THOMAS DA and FORD RR (2005) The Crisis of Innovation in Water and Wastewater ( $1^{\text {st }}$ edn). Edward Elgar, Cheltenham.

TIA (TECHNOLOGY INNOVATION AGENCY, SOUTH AFRICA) (2010) Strategic plan for the fiscal years 2011/12 - 2015/16. URL: http://db3sqepoi5n3s.cloudfront.net/files/docs/110413stratplan_0. pdf (Accessed 27 June 2014).

UNESCO (2010) The Current Status of Science around the World. United Nations, Paris.

WRC (2012) Water Research Commission Annual Report 2011/12. WRC, Pretoria. URL: http://www.wrc.org.za/Pages/DisplayItem. aspx?ItemID=9762 (Accessed 15 June 2013). 